\title{
A prática como componente curricular na formação de professores
}

\author{
Júlio Emílio Diniz-Pereira*
}

\section{Resumo}

Este artigo discute a prática como componente curricular na formação de professores a partir de três perspectivas: 1) uma análise dessa expressão na atual legislação educacional brasileira, ou seja, nos documentos legais sobre Educação que foram produzidos, no País, a partir da aprovação da Lei de Diretrizes Nacionais da Educação Nacional (Lei no. 9.394/96), de 1996; 2) uma discussão, baseada nos trabalhos de John Dewey, sobre as origens das dificuldades de se compreender e se seguir o princípio da indissociabilidade teoria-prática na formação docente e, por fim, 3) a apresentação de algumas possibilidades colocadas pelo movimento pela profissionalização do trabalho docente ï um movimento iniciado nos anos 1980, nos Estados Unidos e Canadá, e que tem como princípios: conceber o ensino como uma atividade profissional apoiada em um sólido repertório de conhecimentos, entender a prática profissional como um lugar de formação e de produção de saberes pelos práticos e estabelecer ligação entre as instituições universitárias de formação e as escolas da Educação Básica.

Palavras-chave: formação de professores; prática como componente curricular; trabalho docente.

\section{Practice as a curriculum component in teacher education programs in Brazil}

Abstract

This article discusses practice as a curriculum component in teacher education from three perspectives: 1. an analysis of this expression at the current Brazilian educational legislation, that means, in the legal documents on Education written, in Brazil, after the National Educational Law was approved in 1996; 2. the

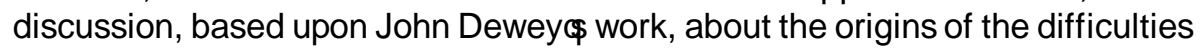
to both understand and follow the principle of no separation between theory and practice in teacher education and, finally, 3. the presentation of some possibilities through the so-called movement for the professionalization of teaching work $і$ a movement started in the $1980 \hat{\mathbf{s}}$, in the United States and Canada, and which

\footnotetext{
* Professor Doutor da Universidade Federal de Minas Gerais, Faculdade de Educação, Departamento de Métodos e Técnicas de Ensino. Belo Horizonte, Minas Gerais ï Brasil.
} 
has principles such as: to conceive teaching as a professional activity based upon a solid knowledge foundation; to understand professional practice as an educational setting and as a place for practitioners produce knowledge; and to establish links between university institutions and elementary, middle and high schools.

Keywords: Teacher education; Practice as a curriculum component; Teaching work.

\section{Introdução}

A partir da crítica ao modelo da racionalidade técnica e orientadas pelo modelo da racionalidade prática, definem-se hoje outras maneiras de representar a formação docente. As atuais políticas para preparo dos profissionais da educação, no país, parecem consonantes com esse outro modo de conceber tal formação. As propostas curriculares elaboradas, desde então, procuram romper com o modelo anterior, revelando um esquema em que a prática é entendida como eixo dessa preparação. Por essa via, o contato com a prática docente deve aparecer desde os primeiros momentos do curso de formação. Desse envolvimento com a realidade prática se originam problemas e questões que devem ser levados para discussão nas disciplinas teóricas. Os blocos de formação não se apresentam mais separados e acoplados, como no modelo anterior, mas concomitantes e articulados. A ideia da ñprática como componente curricularò ganha destaque nessa proposta e é o tema central deste artigo.

Este texto se divide, então, em três partes: na primeira parte, discuto de onde surge a expressão p̃pática como componente curricularòna recente legislação educacional brasileira. ${ }^{1} \mathrm{Na}$ segunda, baseado em textos de John Dewey, faço algumas breves considerações sobre as origens das dificuldades de se compreender e se seguir o princípio da indissociabilidade teoria-prática na formação docente. Por fim, apresento brevemente algumas possibilidades de discussão dessa temática a partir do chamado movimento pela profissionalização do trabalho docente.

\section{De onde surge a expressão óprática como componente curricularô na atual legislação educacional brasileira?}

A expressão ñprática como componente curricularòsurgiu, de maneira explícita, na Resolução CNE/CP 2, de 19 de fevereiro de 2002, que instituiu a duração e a carga horária dos cursos de licenciatura, de graduação plena, de formação de professores da Educação Básica, em nível superior. O texto, em seu primeiro artigo, diz o seguinte:

Art. 1 A carga horária dos cursos de Formação de Professores da Educação Básica, em nível superior, em curso de licenciatura, de graduação plena, será efetivada 
mediante a integralização de, no mínimo, 2800 (duas mil e oitocentas) horas, nas quais a articulação teoria-prática garanta, nos termos dos seus projetos pedagógicos, as seguintes dimensões dos componentes comuns:

I ï 400 (quatrocentas) horas de prática como componente curricular, vivenciadas ao longo do curso;

II ï 400 (quatrocentas) horas de estágio curricular supervisionado a partir do início da segunda metade do curso;

III ï 1800 (mil e oitocentas) horas de aulas para os conteúdos curriculares de natureza científico-cultural;

IV ï 200 (duzentas) horas para outras formas de atividades acadêmico-científico-culturais. (grifos meus)

A Resolução anterior (Resolução CNE/CP 1, de 18 de fevereiro de 2002), que instituiu as Diretrizes Curriculares Nacionais para a Formação de Professores da Educação Básica, em nível superior, curso de licenciatura, de graduação plena, apesar de insistir na articulação das dimensoes teóricas e práticas na formação docente, não utilizou a expressão ñprática como componente curricularòem seu texto.

Como podemos ver nas próximas citações de documentos recentes da legislação educacional brasileira, a principal intenção com a adoção dessa expressão foi esclarecer a diferença, na lei, entre r̃prática de ensinoòe r̃estágio curricular supervisionadoò além de reforçar o princípio da articulação teoria e prática na formação de professores.

Na Lei de Diretrizes e Bases da Educação Nacional (Lei n. 9.394/96) está escrito em seus artigos 61 e 65:

Art. 61. A formação de profissionais da educação, de modo a atender aos objetivos dos diferentes níveis e modalidades de ensino e às características de cada fase do desenvolvimento do educando, terá como fundamentos:

1. a associação entre teorias e práticas, inclusive mediante a capacitação em serviços;

2. aproveitamento da formação e experiências anteriores em instituições de ensino e outras atividades.

Art. 65. A formação docente, exceto para a educação superior, incluirá prática de ensino de, no mínimo, trezentas horas. (grifos meus).

O artigo 65 da LDBEN criou, na verdade, uma grande confusão a respeito do termo ñprática de ensinoò o que levou a Câmara de Educação Superior do Conselho Nacional de Educação a aprovar um Parecer, cuja relatora foi a professora Silka Weber, com orientações para o cumprimento do artigo $65 \mathrm{da}$ 
Júlio Emílio Diniz-Pereira

Lei n. 9.394/96 (Parecer CES 744/97). Esse texto esclarecia:

\begin{abstract}
A prática de ensino constitui o espaço por excelência da vinculação entre formação teórica e início da vivência profissional, supervisionada pela instituição formadora.
\end{abstract}

A prática de ensino consiste, pois, em uma das oportunidades nas quais o estudante-docente se defronta com os problemas concretos do processo de ensino-aprendizagem e da dinâmica própria do espaço escolar. (grifos meus)

É importante ressaltar que o Parecer CES 744/97 trazia, ao final, um îProjeto de Resoluçãoòque fixava orientações para o cumprimento do artigo 65 da Lei 9.394/96 (sobre a obrigatoriedade das 300 horas de ñprática de ensinoò). Ele dizia:

Art. 1 ï A prática de ensino é definida como as atividades desenvolvidas com alunos e professores na escola ou em outros ambientes educativos em, no mínimo, 300 horas, sob acompanhamento e supervisão da instituição formadora;

[...]

Art. 2o ï A prática de ensino deverá constituir o elemento articulador entre formação teórica e prática pedagógica com vistas à reorganização do exercício docente em curso;

Art. 3 ï A prática de ensino deverá incluir, além das atividades de observação e regência de classe, ações relativas a planejamento, análise e avaliação do processo pedagógico;

Art. 4 ï A prática de ensino deverá envolver ainda as diversas dimensões da dinâmica escolar: gestão, interação de professores, relacionamento escola/comunidade, relações com a família. (grifos meus)

Dois anos depois da publicação desse Parecer, um outro documento (Parecer CNE/CP 115/99, de 10 de agosto de 1999), tratando das Diretrizes Gerais para os Institutos Superiores de Educação, foi divulgado e procurou explicitar a concepção de r̃prática de ensinoòcomo r̃articulador do processo de formação dos professoresò conforme se vê a seguir:

A prática de ensino como elemento articulador do processo de formação dos professores tem como objetivo, exatamente, atingir à necessária integração entre teoria e prática, em ambas as vertentes.

De fato, é a prática de ensino desenvolvida na escola, como parte de sua formação profissional, que pode desvelar ao aluno docente problemas pedagógicos concretos, que precisam ser resolvidos no cotidiano do pro- 


\section{A prática como componente curricular na formação de professores}

cesso de ensino e aprendizagem desenvolvido no ensino fundamental. O seu enfrentamento objetivo, sob a supervisão da instituição formadora, estimulará o futuro professor a desenvolver reflexão crítica sobre os conteúdos curriculares que ministra e sobre as teorias a que vem se expondo, ao mesmo tempo que suscitará redirecionamentos ou reorganização da atividade pedagógica que vem efetivando.

Nesse processo de aprender fazendo, o aluno docente tanto aprimora e reelabora seus conhecimentos sobre os conteúdos curriculares pelos quais é responsável e aprofunda o seu entendimento das especificidades dos diferentes momentos de aprendizagem e das características próprias dos alunos das diversas etapas da Educação Básica, como amplia necessariamente a sua compreensão da complexidade do processo educativo formal, que envolve não apenas a relação entre professor e aluno, mas também a própria dinâmica da escola, configurada no seu projeto pedagógico, e expressa nas relações estabelecidas entre os diferentes segmentos escolares e com a comunidade [...]. (grifos meus)

Todavia, a primeira vez que apareceu, na recente legislação educacional brasileira, alguma referência mais explícita à expressão ñprática como componente curricularòfoi no texto do Parecer do Conselho Pleno do Conselho Nacional de Educação (Parecer CNE/CP 009/2001, de 8 de maio de 2001), que tratava das Diretrizes Curriculares Nacionais para a Formação de Professores da Educação Básica, em nível superior, curso de licenciatura, de graduação plena. Ele dizia:

Uma concepção de prática mais como componente curricular implica vê-la como uma dimensão do conhecimento, que tanto está presente nos cursos de formação nos momentos em que se trabalha na reflexão sobre a atividade profissional, como durante o estágio nos momentos em que se exercita a atividade profissional.

Apesar da evolução na compreensão da ideia de ñprática como componente curricularònos documentos anteriores, o Parecer CNE/CP 21/2001, de 6 de agosto de 2001, e o îProjeto de Resoluçãoò anexado a tal documento, que trata da duração e carga horária dos cursos de Formação de Professores da Educação Básica, em nível superior, curso de licenciatura, de graduação plena, continuaram utilizando a expressão ñprática de ensinoòem seus textos, como se pode ver a seguir:

Art. 1ำ A carga horária dos cursos de Formação de Professores da Educação Básica, em nível superior, em curso de graduação plena, será efetivada mediante a integralização de, no mínimo, 2800 (duas mil e oitocentas) horas com a garantia das seguintes dimensões dos componentes comuns: 
I ï 400 (quatrocentas) horas de prática de ensino, vivenciadas ao longo do curso;

II ï 400 (quatrocentas) horas de estágio supervisionado, sob forma concentrada ao final do curso;

III ï 1800 (mil e oitocentas) horas para os conteúdos curriculares de atividades acadêmico-científico-culturais em sala de aula;

IV ï 200 (duzentas) horas para outras formas de atividades acadêmico científico-culturais. (grifos meus)

Porém, algo parecia claro na cabeça dos legisladores até aquele momento: uma coisa era a ñprática como componente curricularòe outra coisa era a ñprática de ensinoòe o r̃estágio supervisionadoò O Parecer CNE/CP 28/2001, de 2 de outubro de 2001, deu nova redação ao Parecer CNE/CP 21/2001, estabelecendo a duração e a carga horária dos cursos de Formação de Professores da Educação Básica, em nível superior, curso de licenciatura, de graduação plena, e esclareceu, de uma vez por todas, o que pretendia dizer o dispositivo legal do artigo 65 da LDBEN ï a obrigatoriedade das 300 (trezentas) horas de p̃ática de ensinoò Por ser de fundamental importância para o esclarecimento das questões aqui colocadas, resolvi reproduzir a seguir uma longa parte do Parecer CNE/CP 28/2001.

[...] dada sua importância na formação profissional de docentes, consideradas as mudanças face ao paradigma vigente até a entrada em vigor da nova LDB, percebe-se que este mínimo estabelecido em lei não será suficiente para dar conta de todas estas exigências em especial a associação entre teoria e prática tal como posto no Art. 61 da LDB.

Só que uma ampliação da carga horária da prática de ensino deve ser justificada.

A prática não é uma cópia da teoria e nem esta é um reflexo daquela. A prática é o próprio modo como as coisas vão sendo feitas cujo conteúdo é atravessado por uma teoria. Assim, a realidade é um movimento constituído pela prática e pela teoria como momentos de um dever mais amplo, consistindo a prática no momento pelo qual se busca fazer algo, produzir alguma coisa e que a teoria procura conceituar, significar e com isto administrar o campo e o sentido desta atuação.

Esta relação mais ampla entre teoria e prática recobre múltiplas maneiras do seu acontecer na formação docente. Ela abrange, então, vários modos de se fazer a prática $[\ldots]$

Assim, há que se distinguir, de um lado, a prática como componente curricular e, de outro, a prática de ensino e o estágio obrigatório definidos em lei. [...]

A prática como componente curricular é, pois, uma prática que produz algo no âmbito do ensino. [...] As- 
sim, ela deve ser planejada quando da elaboração do projeto pedagógico e seu acontecer deve se dar desde o início da duração do processo formativo e se estender ao longo de todo o seu processo. Em articulação intrínseca com o estágio supervisionado e com as atividades de trabalho acadêmico, ela concorre conjuntamente para a formação da identidade do professor como educador.

Esta correlação teoria e prática é um movimento contínuo entre saber e fazer [...].

A prática, como componente curricular, que terá necessariamente a marca dos projetos pedagógicos das instituições formadoras, ao transcender a sala de aula para o conjunto do ambiente escolar e da própria educação escolar, pode envolver uma articulação com os órgãos normativos e com os órgãos executivos dos sistemas. [...]. Pode-se assinalar também uma presença junto a agências educacionais não escolares [...]. Professores são ligados a entidades de representação profissional cuja existência e legislação eles devem conhecer previamente. Importante também é o conhecimento de famílias de estudantes sob vários pontos de vista, pois eles propiciam um melhor conhecimento do ethos dos alunos.

É fundamental que haja tempo e espaço para a prática, como componente curricular, desde o início do curso e que haja uma supervisão da instituição formadora como forma de apoio até mesmo à vista de uma avaliação de qualidade.

[...] ao mínimo legal de 300 horas deve-se acrescer mais 100 horas que, além de ampliar o leque de possibilidades, aumente o tempo disponível para cada forma de prática escolhida no projeto pedagógico do curso. As trezentas horas são apenas o mínimo abaixo do qual não se consegue dar conta das exigências de qualidade. Assim, torna-se procedente acrescentar ao tempo mínimo já estabelecido em lei (300 horas) mais um terço (1/3) desta carga, perfazendo um total de $\mathbf{4 0 0}$ horas.

Por outro lado, é preciso considerar um outro componente curricular obrigatório integrado à proposta pedagógica: estágio curricular supervisionado de ensino entendido como o tempo de aprendizagem que, através de um período de permanência, alguém se demora em algum lugar ou ofício para aprender a prática do mesmo e depois poder exercer uma profissão ou ofício. Assim, o estágio curricular supervisionado supõe uma relação pedagógica entre alguém que já é um profissional reconhecido em um ambiente institucional de trabalho e um aluno estagiário. Por isso é que este momento se chama estágio curricular supervisionado. 
[...]

Tendo como objetivo, junto com a prática, como componente curricular, a relação teoria e prática social [...] o estágio curricular supervisionado é o momento de efetivar, sob a supervisão de um profissional experiente, um processo de ensino-aprendizagem que tornar-se-á concreto e autônomo quando da profissionalização deste estagiário.

Entre outros objetivos, pode-se dizer que o estágio curricular supervisionado pretende oferecer ao futuro licenciado um conhecimento do real em situação de trabalho, isto é, diretamente em unidades escolares dos sistemas de ensino [...]

O estágio curricular supervisionado é pois um modo especial de atividade de capacitação em serviço e que só pode ocorrer em unidades escolares onde o estagiário assuma efetivamente o papel de professor, de outras exigências do projeto pedagógico e das necessidades próprias do ambiente institucional escolar testando suas competências por um determinado período. [...] que este tempo supervisionado não seja prolongado, mas seja denso e contínuo. [...]

Neste sentido, é indispensável que o estágio curricular supervisionado [...] se consolide a partir do início da segunda metade do curso, como coroamento formativo da relação teoria-prática e sob a forma de dedicação concentrada.

Assim, o estágio curricular supervisionado deverá ser um componente obrigatório da organização curricular das licenciaturas, sendo uma atividade intrinsecamente articulada com a prática e com as atividades de trabalho acadêmico.

Ao mesmo tempo, os sistemas de ensino devem propiciar às instituições formadoras a abertura de suas escolas de Educação Básica para o estágio curricular supervisionado [...] por meio de um acordo entre instituição formadora, órgão executivo do sistema e unidade escolar acolhedora da presença de estagiários. Em contrapartida, os docentes em atuação nesta escola poderão receber alguma modalidade de formação continuada a partir da instituição formadora. [...] participação de caráter recíproco.

[...] Sendo uma atividade obrigatória, por sua característica já explicitada, ela deve ocorrer dentro de um tempo mais concentrado, mas não necessariamente em dias subsequentes. Com esta pletora de exigências, o estágio curricular supervisionado da licenciatura não poderá ter uma duração inferior a 400 horas. (grifos meus) 
Para finalizar esta parte do artigo, tem-se a seguir um quadro-resumo das principais orientações contidas na legislação educacional atual sobre a ñpática como componente curricularò de um lado, e o restágio curricular supervisionadoò de outro:

\begin{tabular}{|l|l|}
\hline $\begin{array}{l}\text { "prática como componente } \\
\text { curricular" }\end{array}$ & "estágio curricular supervisionado" \\
\hline mínimo de 400 horas & mínimo de 400 horas \\
\hline desde o início do curso & a partir da segunda metade do curso \\
\hline "ao longo de todo o processo formativo" & em "um tempo mais concentrado" \\
\hline $\begin{array}{l}\text { em outros espaços (secretarias de } \\
\text { educação, sindicatos, "agências } \\
\text { educacionais não escolares", } \\
\text { comunidades) }\end{array}$ & $\begin{array}{l}\text { em escolas (mas não apenas em salas } \\
\text { de aula) }\end{array}$ \\
\hline $\begin{array}{l}\text { orientação/supervisão da instituição } \\
\text { formadora }\end{array}$ & $\begin{array}{l}\text { orientação da instituição formadora e } \\
\text { supervisão da escola }\end{array}$ \\
\hline $\begin{array}{l}\text { orientação/supervisão articulada ao } \\
\text { trabalho acadêmico }\end{array}$ & $\begin{array}{l}\text { orientação articulada à prática e ao } \\
\text { trabalho acadêmico }\end{array}$ \\
\hline & $\begin{array}{l}\text { tempo de supervisão: que não seja } \\
\text { prolongado, mas seja denso e contínuo } \\
\text { tempo de orientação: não definido }\end{array}$ \\
\hline $\begin{array}{l}\text { tempo de orientação/supervisão: não } \\
\text { definido }\end{array}$ & \begin{tabular}{l} 
tado \\
\hline
\end{tabular}
\end{tabular}

Tendo esclarecido o que a recente legislação educacional brasileira entende por ñprática como componente curricularò r̃prática de ensinoòe restágio curricular supervisionadoò passo a discutir, mesmo que brevemente, as origens das dificuldades de se compreender e se seguir, nas nossas instituições de ensino superior, o princípio da indissociabilidade teoria-prática na formação de professores.

\section{Origens das dificuldades de se compreender e se seguir o princípio da indissociabilidade teoria-prática na formação docente}

Em um texto, de 1904, The Relation of Theory to Practice in the Education of Teachers, John Dewey foi categórico ao afirmar que r̃a formação profissional adequada dos professores não é exclusivamente teórica, mas envolve determinada quantidade de trabalho práticoò Ele estava convencido r̃de que a formação teórica, meramente teórica, incompreensível, remota [é] relativamente inútil para o professorò 
Nesse texto, ele continuou defendendo a sua posição ao dizer que T̃á algo de errado no lado đ́cadêmicoôda formação profissional, se, por meio dele, o estudante não obtiver, constantemente, lições práticas da mais excelente qualidadeò Por fim, em termos da formação de professores, Dewey advogou pela ñ̃ormação de hábitos laborais [que] possuem uma aprovação empírica, em vez de uma aprovação científicaò

Apesar de seu convencimento a respeito da natureza teórico-prática da formação de professores, Dewey tinha plena consciência das dificuldades de se traduzir, em termos de propostas curriculares, o princípio da indissociabilidade entre teoria e prática nos cursos de formação docente. Como veremos a seguir, recebemos uma herança cultural muito forte que tende a separar e hierarquizar as atividades de cunho teórico e intelectual, de um lado, e as atividades práticas, manuais e laborais, de outro.

John Dewey publicou, em 1916, o livro Democracy and Education: an Introduction to the Philosophy of Education e discutiu no Capítulo 19 ï Trabalho e Lazer ï as origens da separação entre teoria e prática na cultura ocidental: tal separação é identificada, por Dewey, na Grécia clássica (V-IV a.C.), onde havia uma nítida divisão social entre classes trabalhadoras e classes ociosas. Ele cita Aristóteles (384-322 a.C.) para mostrar a concepção da relação teoria e prática que se tinha naquela época, naquela sociedade:

\section{[...] os escravos, os artesãos e as mulheres são utiliza- dos no fornecimento dos meios de subsistência, de modo que outros, adequadamente equipados com inte- ligência, possam viver sua vida de lazer, ocupando-se de coisas que realmente compensam. (p. 115)}

Portanto, os cidadãos, não precisando trabalhar, podiam dedicar-se ao lazer, às artes e à filosofia.

A esses dois modos de ocupação, que se distinguem em atividades (ou ranrtesŏ livres e servis, correspondem dois tipos de educação: a básica ou mecânica (também chamada de r̂subalternaò) e a liberal ou intelectual. A ñiberalòou livre designa a educação que não visa a formação profissional. Dewey, ao analisar a separação e a hierarquização entre teoria e prática na cultura ocidental, afirma:

Quanto menos o conhecimento se relacionar com assuntos práticos, com manufatura ou com produção, mais adequadamente ele concerne à inteligência. [...] Quanto mais elevada a atividade, mais puramente mental ela é, menos diz respeito às coisas materiais ou ao corpo; quanto mais puramente mental, mais independente ou autosuficiente ela se torna. (p. 118)

Dessa maneira, Dewey conclui que a dicotomia entre o mental (a teoria) e o material (a prática), associando o primeiro ao que é superior e o segundo ao que é inferior, é uma característica da educação grega clássica. 
Assim, a filosofia grega, bem como a educação dela decorrente, formalizou a primazia da razão como algo absolutamente separado dos afazeres práticos ï o conhecimento como pura contemplação.

Por fim, mesmo que a legislação educacional brasileira, no que tange à formação de professores, tenha avançado ao insistir no princípio da indissociabilidade teoria-prática na preparação desses profissionais e, para tal, determinado um aumento significativo da carga horária teórico-prática nas licenciaturas, isso não garante que as nossas instituições de ensino superior seguirão tal princípio e traduzirão em propostas curriculares tal ideia. As origens das dificuldades de se compreender e de se seguir esse princípio, como vimos por meio dessa breve e incompleta discussão, baseada em alguns escritos de John Dewey, remontam ao período da Grécia clássica, berço da nossa civilização, e estão, portanto, profundamente arraigadas em nossa cultura.

Sendo assim, por mais de um século, advoga-se a favor da prática como fonte de aprendizagens múltiplas sobre a docência. Porém, ainda hoje se observa, principalmente nos meios acadêmicos, uma grande resistência em reconhecer isso e, nas instituições de ensino superior, de se utilizar tal princípio para orientar as reformas dos cursos de formação de professores. É importante enfatizar, todavia, que tal resistência não é necessariamente negativa. Vários grupos progressistas e comprometidos com a questão da formação de professores nas universidades temem que a ênfase na dimensão prática possa reforçar as ideias conservadoras e retrógradas que limitam a formação docente ao mero treinamento de habilidades necessárias ao ensino, ou seja, concepções meramente técnicas e instrumentais sobre a formação de educadores.

Para finalizar este artigo, apresento, em linhas gerais, alguns princípios comuns do chamado m̃movimento pela profissionalização do trabalho docenteò Como veremos a seguir, esse movimento traz fundamentos teóricos importantes para a defesa do princípio da indissociabilidade entre teoria e prática na formação de professores e, por via de consequência, novas possibilidades para se repensar a formação de professores no mundo e em nosso País.

\section{Movimento pela profissionalização do trabalho docente: possibilidades²}

Iniciou-se na década de 1980, nos Estados Unidos e no Canadá, o movimento reformista da formação acadêmico-profissional de professores da Educação Básica que buscou refletir sobre a profissionalização do trabalho docente. Esse movimento se espalhou nos países de cultura anglo-saxônica, na Europa francófona, como também em vários países latino-americanos (TARDIF, 2000). Entre os princípios comuns desse movimento, têm-se: conceber o ensino como uma atividade profissional apoiada em um sólido repertório de conhecimentos, entender a prática profissional como um lugar de formação e de produção de saberes pelos práticos e estabelecer ligação entre as instituições universitárias de formação e as escolas da Educação Básica. 
A discussão acerca dos saberes docentes foi iniciada, no Brasil, por meio do artigo de Tardif e colaboradores (Os professores face ao saber. Esboço de uma problemática de um saber docente, 1991), publicado na revista Teoria \& Educação. Esboço, a seguir, uma tentativa de diálogo entre três pesquisadores representativos desse campo de conhecimento: Lee Shulman, Maurice Tardif e Clermont Gauthier.

Shulman (1986), no artigo ñThose who understand: Knowledge Growth in Teachingò distingue três categorias de conhecimentos presentes no desenvolvimento cognitivo do professor. São eles: Subject matter content knowledge ñ conhecimento sobre a matéria ensinada; Pedagogical content knowledgeñ conhecimento didático da matéria; Curricular Knowledge ñ conhecimento curricular.

Shulman explicitou e detalhou essas três formas de conhecimento, mas reconheceu a existência de várias outras. Todas elas se manifestariam de três modos: por meio do conhecimento proposicional, conhecimento de caso e conhecimento estratégico.

O conhecimento proposicional, de caráter assertivo, se manifesta de três maneiras no ensino: por meio dos princípios, máximas e normas. Os princípios seriam fatos empiricamente ou filosoficamente discutidos, as máximas derivam da experiência prática e as normas são raciocínios éticos. Vou me ater às máximas que r̃aão ideias que nunca foram confirmadas por pesquisa e seriam em princípio difíceis de demonstração. No entanto, essas máximas representam a sabedoria acumulada da prática e em muitos casos são guias tão importantes para a prática como a teoria ou princípios empíricosò(SHULMEN, 1986, p.11). As máximas podem ser identificadas como conselhos, proposições sobre e para a prática pedagógica. Podemos perceber a semelhança entre 0 que Shulman chamou de r̃máximasòe o que Tardif denominou r̃saberes experienciaisò

\begin{abstract}
Recordamos que essas são fiformasò entre as quais cada uma das categorias gerais de conhecimento discutidas anteriormente ï conteúdo, pedagogia e currículo ï podem ser organizadas. (Existem outras categorias importantes de conhecimento, como por exemplo: as diferenças individuais entre os alunos, os métodos de organização e gestão da sala de aula, a História e Filosofia da Educação e a administração escolar, para citar apenas algumas. Cada uma dessas categorias poderão ser subdivididas e exprimíveis através das formas de conhecimento discutidas aqui. (SHULMAN, 1986, p.10)
\end{abstract}

Segundo Tardif (2002), os saberes docentes têm uma origem plural. Dentre as diversas origens (saberes pessoais, da formação escolar, dos programas e livros didáticos, da formação profissional, etc.), destaco os saberes provenientes da experiência na profissão, os saberes adquiridos por meio da práti- 
ca. O autor explica que os saberes da experiência ou da prática são aqueles adquiridos e consolidados por intermédio da prática cotidiana da profissão docente e que não provêm dos cursos de formação ou currículos. Esse saber pode ser transmitido ou trocado entre os pares, os professores em exercício. A troca de experiências é uma das formas em que o saber da experiência é objetivado e assim passível de ser registrado.

\begin{abstract}
É através das relações com os pares e, portanto através do confronto entre os saberes produzidos pela experiência coletiva dos professores, que os saberes experienciais adquirem uma certa objetividade: as certezas subjetivas devem ser, então, sistematizadas a fim de se transformarem num discurso de experiência capaz de informar ou de formar outros docentes e de fornecer uma resposta a seus problemas. (TARDIF, 2002, p. 32)
\end{abstract}

O trabalho de Tardif e colaboradores concentra-se na categorização e na análise das origens dos saberes docentes, destacando a pluralidade e heterogeneidade destes. Gauthier e colaboradores (1998) defendem um rofício feito de saberesòe constroem um repertório de saberes, classificando e reorganizando os resultados de pesquisas realizadas em sala de aula (principalmente norte-americanas) que buscam investigar os conhecimentos dos professores por meio de suas interações com seus alunos.

Para Tardif, esses conhecimentos podem também ser estudados por intermédio da relação entre pares (os professores em exercício). Segundo ele, professores experientes e iniciantes trocam saberes entre si e nessa troca os saberes são objetivados e passíveis de serem pesquisados.

Gauthier et al. (1998) defendem uma profissionalização do trabalho docente, destacando a importância de se organizar um repertório de conhecimentos do ensino construído a partir da prática dos professores. Esse repertório não seria normativo ou prescritivo, mas consultivo. A ideia não é transformar os resultados levantados em normas a serem seguidas pelos professores, mas sim em senhas, guias que podem merecer um exame atencioso pelo docente. Assim como Tardif, Gauthier argumenta que não se deve fazer uma simples compilação dos conhecimentos, mas antes submetê-los a uma validação científica. Em sua organização, Gauthier inclui uma categoria para os saberes experienciais que foram tornados públicos e testados: os saberes da ação pedagógica.

Portanto, como vimos, o m̃movimento pela profissionalização do trabaIho docenteòdisponibiliza, por meio de suas pesquisas conceituais e empíricas, uma fundamentação teórica de qualidade para a defesa do princípio da indissociabilidade teoria-prática na formação de professores e traz, consequentemente, novas possibilidades para a implementação de inovações 
curriculares, que sigam esse princípio, nos cursos de formação docente.

\section{Considerações finais}

À guisa de conclusão, é importante ressaltar que, em função da necessidade urgente de se habilitar aqueles que, hoje, no País, estão em sala de aula, exercendo o magistério, corre-se o risco de as recentes políticas educacionais para formação docente favorecerem a improvisação no preparo dos profissionais da educação. Em nome dessa urgência, a prática, que deve ocupar um espaço significativo nas grades curriculares dos cursos de licenciatura, pode ser compreendida erroneamente como formação em serviço. As horas trabalhadas em sala de aula, sem, necessariamente, um planejamento e uma intencionalidade formativa, podem, assim, ser contabilizadas nos novos cursos de licenciatura pelos profissionais já em exercício na escola. Como consequência, diminui, significativamente, a carga horária dos cursos de formação inicial de professores, o que, obviamente, não é desejável e representa um imenso retrocesso em termos da preparação desses profissionais.

Do mesmo modo, o descuido com o embasamento teórico na formação de professores, indispensável no preparo desse profissional, é extremamente prejudicial aos cursos de licenciatura. O rompimento com o modelo que prioriza a teoria em detrimento da prática não pode significar a adoção de esquemas que supervalorizem a prática e minimizem o papel da formação teórica. Assim como não basta o domínio de conteúdos específicos e/ou pedagógicos para alguém se tornar um bom professor, também não é suficiente estar em contato apenas com a prática para se garantir uma formação docente de qualidade. Sabe-se que a prática pedagógica não é isenta de conhecimentos teóricos e que estes, por sua vez, ganham novos significados quando diante da realidade escolar.

\section{Referências}

BRASIL. Lei n. 9.394, de 20 de dezembro de 1996. Estabelece as Diretrizes e Bases da Educação Nacional. Diário Oficial da União. Brasília, DF, 20 dezembro. 1996.

CONSELHO NACIONAL DE EDUCAÇÃO. Câmara de Educação Superior. Parecer CNE/CES 744/97. Orienta sobre o cumprimento do Artigo 65 da Lei n. 9.394/96.

CONSELHO NACIONAL DE EDUCAÇÃO. Conselho Pleno. Parecer CNE/CP 115/99 de 10 de agosto de 1999. Sobre as Diretrizes Gerais para os Institutos Superiores de Educação.

. Conselho Pleno. Parecer CNE/CP 009/2001 de 09 de maio de 2001. Sobre as Diretrizes Curriculares Nacionais para a Formação de Professores da Educação Básica, em nível superior, curso de licenciatura. 
CONSELHO NACIONAL DE EDUCAÇÃO. Conselho Pleno. Parecer CNE/CP 21/2001, de 06 de agosto de 2001. Duração e carga horária dos cursos de Formação de Professores da Educação Básica, em nível superior, curso de licenciatura, de graduação plena.

CONSELHO NACIONAL DE EDUCAÇÃO. Conselho Pleno. Parecer CNE/CP 28/2001 de 02 de outubro de 2001. Dá nova redação ao Parecer CNE/CP 21/ 2001, estabelecendo a duração e a carga horária dos cursos de Formação de Professores da Educação Básica, em nível superior, curso de licenciatura, de graduação plena.

Conselho Pleno. Resolução CNE/CP 01/2002 de 18 de fevereiro de 2002. Institui as Diretrizes Curriculares Nacionais para a Formação de Professores de Educação Básica, em nível superior, curso de licenciatura, de graduação plena.

Conselho Pleno. Resolução CNE/CP 02/2002 de 19 de fevereiro de 2002. Institui a duração e a carga horária dos cursos de licenciatura, de graduação plena, de Formação de Professores da Educação Básica em nível superior.

DEWEY, J. The Relation of Theory to Practice in Education of Teachers. National Society for the Scientific Study of Education, Third Yearbook, Part I, Bloomington: Public School Publishing Co., 1904, p. 9-80.

Democracy and Education: an Introduction to the Philosophy of Education. New York: Macmillan, 1916.

GAUTHIER, C. et al. Por uma teoria da Pedagogia. Rio Grande do Sul: Editora Unijuí, 1998.

SHULMAN, L. Those who understand. Knowledge growth in teaching. Educational Researcher, v. 15, 1986.

TARDIF, M.; LESSARD, C.; LAHAYE, L. Os professores face ao saber. Esboço de uma problemática de um saber docente. Teoria \& Educação n 04, 1991.

TARDIF, M. Saberes profissionais dos professores e conhecimentos universitários para uma epistemologia da prática profissional dos professores e suas consequências em relação à formação para o magistério. Revista Brasileira de Educação, v.13, 2000.

TARDIF, M. Saberes docentes e formação profissional. Petrópolis: Editora Vozes, 2002.

\footnotetext{
Notas

1 Refiro-me aos documentos legais sobre educação que foram produzidos no País a partir da elaboração e aprovação da Lei de Diretrizes e Bases da Educação Nacional (Lei n. 9.394/96), em 1996.
} 


\section{Júlio Emílio Diniz-Pereira}

2 Esta parte do texto foi escrita com a colaboração da minha orientanda de Mestrado, Mariana Costa Lopes da Silva.

\section{Correspondência}

Júlio Emílio Diniz-Pereira ï Rua Castelo de Windsor, 206 Apt. 501, Bairro Castelo, Belo Horizonte, Minas Gerais, 31.330-180, Brasil.

E-mail: juliodiniz@ufmg.br

Recebido em 17 de março de 2011

Aprovado em 21 de junho de 2011 